\title{
THE IMPACT OF FLIP LEARNING SYSTEM AS SUPPORTING STRATEGY WITHIN THE COVID19 PERIOD AND AFTER
}

\author{
Alwaleed Mohamed Abdullah Alshengiti ${ }^{1 i}$, \\ Rabab Alshaiekh Idres Musa ${ }^{2}$ \\ ${ }^{1}$ General Manager, \\ Development Department, \\ Alkhaleej Training and Education, \\ Riyadh, Saudi Arabia \\ ${ }^{2}$ Lecturer, College of Science \& Humanities, \\ Prince Sattam bin Abdulaziz University, \\ Kharj, Saudi Arabia
}

\begin{abstract}
:
Purpose: Flipped Learning is an educational approach that combines the traditional classroom with online tools to find its best method in the Flipped classroom where the responsibility for the teaching process is somehow shifted to the students who have direct access to the lesson's contents before going to school. In this strategy, the instructor becomes an information facilitator and leads students in the transition from lecturing to the acquisition exercise of abilities and competencies. This paper explores E-learning approaches and the exceptional strategies implications students may additionally have. It also illustrates how such activities and methodologies can be a complete learning system. Methods: Furthermore, the most appropriate way to carry out Flipped teaching has been to create virtual classes on social media such as Facebook, Edmodo, Zoom, and Microsoft Teams which are also helpful as a sort of online discussion forum between the teacher and their students. From this new perspective, students have experienced new techniques and methods through cooperative Learning, a teaching/learning model that allows them to figure together in small groups to achieve the same goals. In addition, students can create digital products and post them on the Internet, thereby attaining great results. Results: All the activities are planned to require critical thinking and different learning styles at the end, supporting the idea of individual Learning rather than group learning.
\end{abstract}

Keywords: flipped learning, flipped classroom, cooperative learning, social media

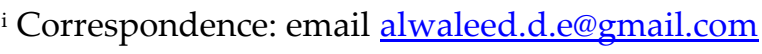




\section{Introduction}

Early 2020, a sudden pandemic is later known as Covid19, spread all over the world. The immediate action of education authorities was taken after a short break period to shift the learning system from face-to-face (traditional) learning to virtual learning across the Gulf. We aimed in this paper to investigate the impact of the flipped learning strategy as a supporting strategy during Covid19 and whether it can be shifted as a complete learning system.

Flipped Learning is becoming increasingly relevant in teaching. It is a replacement learning strategy that incorporates online and face-to-face modalities. The two approaches integrate and blend one another, 'blending' and enhancing a positive learning environment. This learning strategy works through the computer-mediated activity using tablets, smartphones, and other technological devices, which catch students' interests more effectively than simply face-toface or online lessons. Naturally, Flipped Learning involves a series of methodologies and activities which will be considered to accomplish levels A2, B1, B2, and C1 of the Common European Framework of Reference. One of the best ways to organize Flipped Learning is the flipped classroom, where students are asked to watch a video, view a site, or online articles at home before coming to class. Once they are asked to go to class, they discuss the new material learned on the Internet through cooperative activities, exploring topics for inquiry-based learning. However, it's necessary to form a review of students' work frequently to pinpoint what should be repeated, revised, or expanded. A key to a successful flipped classroom, especially in project-based learning activities, is to encourage learners to positively apply the new information to different contexts in a creative way. Consequently, students are responsible for their own Learning, and teachers help them in the process of leading and coaching and become supporters, facilitators in developing the ability to compare, share, and differentiate opinions. For all these reasons, Flipped Learning should be considered in the context of the challenges and opportunities given to education to provide a truly personalized approach for every student.

\section{Literature Review}

\subsection{What is Flipped Learning?}

Flipped study classrooms where the responsibility of the learning process is by some means shifted to the students who have exposure to the contents of the lesson before going to school. In this regard, the instructor will become a leader, facilitator and assist students in shifting from knowledge to acquisition of skills and competencies

From an academic viewpoint, "flipping" as a learning technique focuses on initiating a student-centered learning environment that influences technology and emphasizes utility and collaboration (Fitzpatrick, 2012).

Argues about the flipped studying permits educators to "break the lecture-centered instructing model by shifting the focus from the curriculum stepping guide to student mastering needs." (Hamdan, McKnight, McKnight, \& Arfstrom, 2013, p. 3).

According to its supporters, the flipped learning model allows "students [to] obtain first publicity to new fabric backyard of class, generally through studying or recorded lesson videos, and then 
use category time to do the higher stage of assignments and difficult work of integrating that knowledge, via problem-solving, discussion, grouping and regrouping or debates. In terms of Bloom's revised taxonomy (2001), this means that students are doing the lower levels of cognitive work (gaining understanding and comprehension) at home and focusing on the higher types of cognitive work (application, analysis, synthesis, and evaluation) in class, the place where they have peer guide of their classmates and instructor" (Brame, 2013)

A flipped classroom is an "educational method in which direct education strategies move from the team mastering house to the person getting to know space, and the school team space is modified into a dynamic, interactive studying environment where the educator guides students as they practice standards and have interaction creatively in the problem matter" (The Flipped Learning Network, 2014).

The term FL derives from Baker's (2000) phrase "the study room flipped" (p. 9). More recently, Bergmann and Sams (2012) described FL in this way. What is historically accomplished in classification is completed at home, and what is traditionally carried out as homework is done in class. Learners start at home, studying with video lectures or screencasts through themselves before the class, and then interact strongly to the level that helps them practice content material to a deeper degree (Bergmann and Sams, 2013; Collins et al., 2001; Covil et al., 2013; Gannon et al.)

\subsection{The four Pillars of FIIP "F"}

Flipped Learning allows for various learning methods; educators often rearrange their learning to accommodate a lesson or unit to support group work or independent study. They create flexible spaces in which the student chooses where and when they learn. Furthermore, educators who flip their classes are flexible in their expectations of students' timelines for Learning and assessing student learning.

\section{"L"}

In the traditional teacher center model, the teacher is the primary source of information. By contrast, the flip learning model deliberately shifts the mode to a learner-centered approach. Where in-class time is dedicated to exploring topics in greater depth, that will create rich learning opportunities. As a result, students are actively involved in knowledge construction as they participate in and evaluate their learning in a manner that is personally meaningful. "I"

Intentional content, Flipped Learning Educators continually think about how they can use Flipped Learning model to help students develop conceptual understanding, as well as procedural fluency. They determine what they need to teach and what materials students should explore on their own. Educators use international content to maximize classroom time to adopt methods of student-centered, active learning strategies, depending on grade level and subject matter.

"P"

The role of a professional educator is even more critical and often more demanding in a Flipped Classroom than in a traditional one. During class time, they continually observe their students, 
providing them with feedback relevant to the moment and assessing their work. Professional Educators are reflective in their practice, connect to improve their instruction, accept constructive criticism and tolerate controlled chaos in their classroom. While Professional Educators take on less visibly prominent roles in flipped classrooms, they remain the essential ingredient that enables Flipped Learning to occur.

\subsection{Previous Studies}

\section{A. Blended Learning Studies}

Studies on blended mastering Although traditional forms of BL include a mix of face-to-face instructor-led lectures and supplementary online activities (Garrison and Kanuka, 2004; Ginns and Ellis, 2007; Kember et al., 2010; Kerres and de Witt, 2003), BL students and practitioners have long sought to discover the optimal mixture of the two mastering techniques.

According to a thematic synthesis of BL research carried out via Halverson et al. (2014), publications on BL from 2000 via 2011, on the whole, wondered about learning format troubles like models, strategies, and course structure. For example, the didactical $3 \mathrm{C}$ model developed by means of Kerres and de Witt (2003) involves a framework specifying three components of BL and corresponding getting to know tasks. The three elements of BL were: (1) a content material component that makes factual mastering content material accessible to learners, (2) a communication factor that affords interpersonal interactions for extra complicated or arguable studying tasks between students or learners and instructors, and (3) a positive issue that enables learners' active engagement in most complicated studying tasks.

Blended Learning is becoming increasingly applicable in teaching. It is a new methodology that consists of online and face-to-face modalities. The two strategies combine and mix each other, 'blending' and improving an advantage of gaining knowledge of the environment. This academic approach combines the traditional type with computer-mediated endeavor through the use of tablets, smartphones, and other technological units, which seize students' interests more efficiently than actually face-to-face or online lessons. Naturally, blended Learning involves a sequence of methodologies and activities that can be viewed to accomplish ranges B1, B2, and C1 of the Common European Framework of Reference. One of the excellent approaches to organizing blended getting to know is the flipped study room, the place students are asked to watch a video, view a web page, or online articles at home before coming to class. Once they have come to college, they discuss the new lesson learned on the Net via cooperative activities, exploring subjects for an inquiry-based totally on Learning. However, it is critical to make an evaluation of students' work often to pinpoint what ought to be repeated, revised, or expanded.

\section{B. Flipped Learning Studies}

The FL lookup literature can also be divided into research with conceptual or empirical discussions.

The conceptual studies situation definitions, comparisons with standard approaches, educational rationales, and difficulty appropriateness of FL (e.g., Bergmann and Sams, 2013; Bishop and Verleger, 2013; Bush, 2013; Mason et al., 2013; Milman, 2013). 
While the experiential studies usually report on the effectiveness of actual instances of FL coaching and encompass implications for layout that can guide possible practitioners (e.g., Covil et al., 2013; Herreid and Schiller, 2013; Slomanson, 2014; Strayer, 2012; Talbert, 2012).

The term FL derives from Baker's (2000) phrase "the classroom flipped" (p. 9). More recently, Bergmann and Sams (2012) described FL in this way: in this way: what is historically carried out in classification is achieved at home, and what is traditionally executed as homework is completed in class. Learners begin at home, getting to know with video lectures or screencasts by using Table 1 Blending suggestions in associated BL theories Face-to-face Online Didactical 3C model (Kerres and Witt, 2003).

Communication factor that presents interpersonal interactions for extra detailed or arguable gaining knowledge of duties, Constructive factor that helps beginners to interact in most complicated actively, Mastering tasks, a Content factor that makes factual gaining knowledge of content reachable to learners Cost of conversation (Hollingshead, 1996; Kerres and Witt, 2003).

A magnificent strength of the online getting-to-know environments is that they can easily provide visual representations like area simulations or comparisons and enable self-pacing (Bush 2013; Goodwin and Miller 2013). The F2F learning environment can be most likely optimum media for crew work, though sharing with one-to-one assistance, instant support, and personal inspiration. Thus, by way of flipping or inverting the allocation of time and locations for Learning, FL combines two sorts of gaining knowledge of activities - active problem-solving mastering activities and direct instruction/mastery getting to know activities (Bishop and Verleger, 2013) - while making each strategies core factors of a coherent and meaningful learning trip (Stannard, 2012).

Most FL literature stresses that the essential trouble in making FL profitable is structuring online and F2F mastering experiences. Each factor coherently helps the other at the macro-course stage and micro-lesson stage (Ginns and Ellis, 2007). Most researchers commenting on the macrocourse level emphasize the want for an awful lot tighter hyperlink between the online and F2F modes of Learning (Bush, 2013; Covil et al., 2013; Mason et al., 2013; Stannard, 2012; Strayer, 2012). To attain an applicable macrostructure, the lecture part of getting to know has to be stored to a minimum, and the inquiry, discovery, and application components of the learning manner be allocated most time (Stannard, 2012).

Assessment of FL publications consists of a variety of devices designed to consider higherorder wandering competencies like vital and innovative wandering capabilities and problemsolving abilities alongside content mastery (McLaughlin et al., 2014). The assessment additionally should furnish learners with more than one way to show their appreciation (Milman, 2013). Studies investigating the graph of online sessions incorporates three important concerns: (1) physical aspects of online lectures, such as length, speed, and auditory fantastic (Bush, 2013; Goodwin and Miller, 2013; Hattie, 2008; Khan, 2012; Mason et al., 2013; Smith and McDonald, 2013); (2) content points of online lectures, such as acceptable allocation of online portions, interactivity, and clarity (Bush, 2013; Goodwin and Miller, 2013; Milman, 2013; Shim, 2013; Smith and McDonald, 2013); and (3) logistic points outdoor of the online lecture, such as 
formative evaluation, scheduling, and after-activity (Bush, 2013; Mason et al., 2013; Slomanson, 2014; Talbert, 2012).

The fundamental F2F was getting to know pastimes can be designed around duties or problems. Studies supply guidance on the superior facets of the classroom tasks and difficulties of the FL. First, they ought to characterize the most challenging components of studying in the course, and accordingly, may additionally require an instructor's guide, feedback, or peer learner collaboration (Talbert, 2012). The duties also have to be proper and intrinsically lucrative as newcomers observe what they learned in the online lecture (Mason et al., 2013). The instructor no longer solely grants direct and immediate remarks and corrects learners' misconceptions (Goodwin and Miller, 2013); however also responds to their social and emotional desires (Bergmann and Sams, 2012). As external design factors, after-class activities can be designed to inspire in addition reflection that consolidates Learning (Covil et al., 2013). Some practitioners additionally suggest setting clear ground guidelines or fabulous boundaries and growing a superb enticing lifestyle for the profitable implementation of F2F classes in FL (Hamdan et al., 2013; Smith and McDonald, 2013; Talbert, 2012). Table 2 summarizes the micro-level elements/issues to be regarded when designing FL from preceding studies.

\subsection{Flipped Learning Models}

Flipped studying models Turning culture upside down Lee and Recker (2013) present a simple model of a flipped classroom. They say the standard model is upside down, leading to low learner retention and software rates, even though instructors are attempting hard to interact with students in the classroom. Instead of focusing the bulk of instructor assets on the presentation of fabric and leaving college students with little support for the practice, the flipped model sincerely refocuses direction, time, and resources. Students watch a video lecture on their own time and then collaborate with each other outdoors and inside the classroom where they have guidance as they discover, practice, and apply. This model is a precise starting point for those new to flipped learning. Lee and Recker (2013) oversimplify flipped learning with the aid of the usage of the ordinary lecture as the groundwork for all new Learning. However, the model encourages application and discovery, rather than greater routine assignments, as the first-class use of lecture room time. JWL 27,2 164 Downloaded by means of Doctor Zane Berge at 06:41 three March 2015 (PT) Gerstein's Flipped Classroom Model Jackie Gerstein the Flipped Classroom Model in 2011 to provide some staying strength to the trend of flipping. It is undoubtedly a "cycle of gaining knowledge of models" (Gerstein, 2011, para. 10) that is based on the Experiential Learning Cycle and Huitt (2009) Cycle of Instruction. It also corresponds nicely to Bloom's Taxonomy. There are four elements to this model. As shown in Figure two, Gerstein (2011) suggests that the method starts with experiential engagement that gets students involved in the subject. However, this would possibly be extra gorgeous for the classroom; the place students meet on ordinary groundwork as opposed to a shorter place of business studying event. Gilbert (2013) starts off evolving the method with thought exploration. 


\subsubsection{Concept Exploration}

Concept exploration is an educator-led section of the technique that introduces students to what they are learning. This is traditionally the lecture or presentation phase of a course. In a flipped mastering environment, inexperienced persons are allowed extra management over this phase of the mastering cycle than they might have traditionally. Educators assign a quick video or audio lecture, Web sites or different substances to explore. Learners then get to take control of their getting to know by using reading, watching, exploring, and listening to these factors at their personal tempo and level. Educators can also provide college students even extra control by permitting them to find and share sources (Gerstein, 2011; Gilbert, 2013). Some students may additionally pick to dive deeper than they would be capable of in a traditional schoolroom setting. Note that this phase no longer wants to be science-heavy; videos, podcasts, and other media-rich technologies are no longer imperative for flipped learning. Students can additionally use textbooks, newspapers, journal and journal articles, a user manual, or any other low-tech material to explore a topic.

\subsubsection{Meaning-making}

After exploring a new concept, however, before coming to the classroom, students make that meaning out of the statistics they have watched, listened to, or read. Instructors might use a wide variety of strategies for this phase. Those who most favor inspiring peer-to-peer gaining knowledge would possibly have a social networking crew or dialogue board in which college students participate. Those who are most concerned with ensuring that the students come to a category organized might have a quiz or different comprehension check in Figure 1. A simple model for flipping the lecture room a hundred sixty-five Flipped gaining knowledge of in the workplace Downloaded by way of Doctor Zane Berge at 06:41 3 March 2015 (PT) addition, and instructors may also ask college students to mirror on what they learned thru a blog, short video, podcast or different presentation (Gerstein, 2011; Gilbert, 2013). Regardless of the type of things to be used in this stage, students are working towards appreciation level objectives. Experiential engagement. Whether this stage happens before thought exploration or after meaning-making, it will be the first time the learner and teacher are interacting collectively on this content. When used before thought exploration, educators would possibly have their students take tests or play a game that piques their activity in a topic. When used after meaning-making, students are capable of following what they have learned. They would possibly complete a simulation, practice an ability, or work on an artwork project.

Application is taking place at this stage in a way that permits the instructor to judge student understanding, suitable guide activities, assist students that are having difficulties, and grant extra challenges to students that discover the preliminary software convenience (Gerstein, 2011; Gilbert, 2013). Demonstration and application. In the ultimate stage of the Flipped Classroom Model, students analyze, consider and create. Instructors additionally have a risk to evaluate for mastery and provide extra support to students that want more practice. The creation of a personalized venture or presentation might also occur within or backyard of the classroom; however, it ought to continually be shared with the trainer and peers. This goes past reflection 
and private grasp in that students have to create something that is individualized and extends past the lesson with applicability to the learners' everyday lives (Gerstein, 2011, para. 23).

\subsection{Concerns about Flipped Learning}

Skeptics of Flipped Learning say that there is little that is new in it. They say those correct teachers continually try to meet the wants of individual students and use the tools that will help them do that. That is true. And, as stated previously, the practicable of Flipped Learning lies no longer in the movies but in how delivering direct guidance in a specific environment opens up time and house inside the schoolroom to engage in more outstanding leverage learning practices and individualize Learning. Teachers want to be thoughtful about how to maximize the probability for students to turn out to be energetic learners who are empowered to take charge of their personal Learning. Even critics are well known that the changeover to the Flipped Learning model encourages teachers to re-examine their instruction (e.g., Stumpenhorst, 2012). Another difficulty is voiced by means of teachers and others who believe Flipped Learning undervalues the power of engaging face-to-face teaching. Critics fear they won't have the opportunity to do that form of instruction because class time is devoted to college students collaborating, student-generated and -led activities, and other interactive exercises. However, Marshall (2013) points out that teachers are more necessary than ever in Flipped Learning. However, instead of the trainer lecturing to students, their role is to "lead from behind." In other words, the trainer has the tasks of "observation, feedback, and assessment" and guiding the learners' thinking in the best spirit of the Socratic Method. The difference, and perhaps a primary benefit, according to Marshall (2013), is that this practice is spontaneous, cannot be planned out, and is applicable for the students at that moment. Furthermore, the newcomers themselves can fill these equal three roles as they study and grant remarks to each other during category and as they examine their personal Learning. Gary Stager, an educator, speaker, and journalist, is a critic of Flipped Learning. He voiced three primary worries in the course of a 2012 radio debate with Aaron Sams on Southern California Public Radio (2013). First, he asserts that the model emphasizes traditional homework and lectures, although their function is flipped. Second, he says that the demand for Flipped Learning results from flaws in the curriculum, which require that students find out about time beforehand of time. Finally, he argues that the Flipped Learning model is a skill of standardizing Learning. The issue is that in the future that the direct preparation delivered by way of video will be outsourced to mediocre, lower-priced instructors to change greater highly paid veteran teachers. "I am certain many of my colleagues across central Illinois thought I had indeed flipped out... We had been proposing the entire excessive school staff. Our failure rate was absolutely too high to accept. Principal Don Willett and I set out to alternate the route of our schooling content material delivery machine - and in the end, the lives of our 350 students." Patrick Twomey, Superintendent, Havana School District \#12 Havana, White Paper Flipped Learning 12 Should Flip Learning to devolve into little more than lectures and routinized, low-level homework exercises; Stager would simply have a point. A learning model is, however, a framework and, whether it succeeds or not, relies almost entirely on the implementation. Boring lectures can be delivered digitally almost as easily as they can be in type and class time in a Flipped Learning model may want to be taken up with filling out worksheets and doing 
computerized drills. But that is no longer the intent, nor is it inevitable. Indeed, educating successfully in a flipped lecture room is even greater stressful than is usual teaching.

So, if Flipped Learning is to succeed, teachers will want to be trained and supported in how to have to interact with students extra deeply in content. In regard to Stager's problem about mass-produced, cheaply made videos turning into the mainstay of flipped classrooms, Sams and Bergmann suppose that the model works quality when instructors make their personal videos for their own classes. However, the use of videotaped instructions does make it feasible for the teacher to discover gorgeous training produced by means of others, such as those discovered on Khan Academy or TED-Ed. Those training may want to introduce college students to a choice fashion of instructing or supplement training on topics or provide classes in areas in which their trainer is now not an expert. Another situation that is raised is that not all students have to get entry to the high-speed Internet or computers. While this is a professional concern, it has to be cited that homes get admission to computer systems, and the Internet has extended notably over the last two decades. In 2010, nearly six out of each and every ten teenagers a while 3 to 17 used the Internet, and almost $85 \%$ had to get right of entry to a laptop at home. Moreover, the approaches that even low-income college students can access digital content material are increasing rapidly. (Child Trends, 2012) Flipped Learning would possibly no longer work for all educators and students. Not all educators are profitable in their implementations, and there have been college students who, after trying the flipped lecture room experience, choose traditional Learning. In their book, Bergmann and Sams (2012) noted that for decreasing basic grades, Flipped Learning would possibly be appropriate for certain lessons or units, however now, not entire classes. Moreover, as we illustrate during this paper, more qualitative and quantitative lookup desires to be accomplished to become aware of how the doable of the model can be maximized. The current lookup honestly demonstrates that the Flipped Learning model can be one way to create a classroom environment that is learner-centered. This is something that most teachers favor to do however are confined by way of the contemporary organization of faculties and other barriers. Michael Gorman (2012) found that any.

Learner-centered education would provide things to do in the schoolroom that is actionbased, authentic, linked and collaborative, innovative, high level, engaging, ride-based, undertaking-based, inquiry-based, and self-actualizing. The Flipped Learning model affords that bridge to a learner-centered schoolroom environment, thereby enabling deeper studying (Bergmann \& Sams, 2012) that educators are seeking.

\section{Purpose of the Study}

This study intends to attain the subsequent objectives:

1) To analyze the impact of Flipped Learning as a supporting strategy during Covid19.

2) To assess the usage of the Flipped Learning as a supporting strategy during Covid19.

3) To measure whether the Flipped Learning as a supporting strategy during Covid19 can be shifted from supporting strategy to a full learning system. 


\subsection{Significance of the Study}

The study concentrates on analyzing the impact of Flipped Learning as a supporting strategy during Covid19.

\subsection{Research Questions}

The study targeted to analyze the following questions:

1) What is the impact of Flipped Learning as a supporting strategy on EEL learners' performance at the time of the pandemic Covid19?

2) To what extent does Flip Learning as a supporting strategy during Covid19 can be developed into a full learning system from their perspectives?

\section{Methodology}

This research is a qualitative descriptive study. The data used in this paper is obtained through a questionnaire distributed via Google forms. The questionnaire is distributed to determine teachers' responses to the impact of Flipped Learning as a supporting strategy during Covid19.

The population for the study is the teachers of the Direct English Language system in Saudi Arabia. The sampled group is made up of 22 male and female teachers in the English group of teachers experienced in the system. Before subjecting the participants to the e-questionnaire, a request was made to both the group administrators and members on the intent of it, and the link was shared via the group WhatsApp platforms.

The major tool for data collection in this study is a questionnaire.

\subsection{Data Analysis}

Statement 1: I am satisfied with the virtual learning experience.

Table 1: Virtual learning experience

\begin{tabular}{|l|l|c|c|c|c|}
\hline SM1 & & & \\
\hline & & Frequency & Percent & Valid Percent & Cumulative Percent \\
\hline \multirow{3}{*}{ Valid } & Neutral & 2 & 9.1 & 9.1 & 9.1 \\
\cline { 2 - 6 } & Agree & 10 & 45.5 & 45.5 & 54.5 \\
\cline { 2 - 6 } & Strongly agree & 10 & 45.5 & 45.5 & 100.0 \\
\cline { 2 - 6 } & Total & 22 & 100.0 & 100.0 & \\
\hline
\end{tabular}




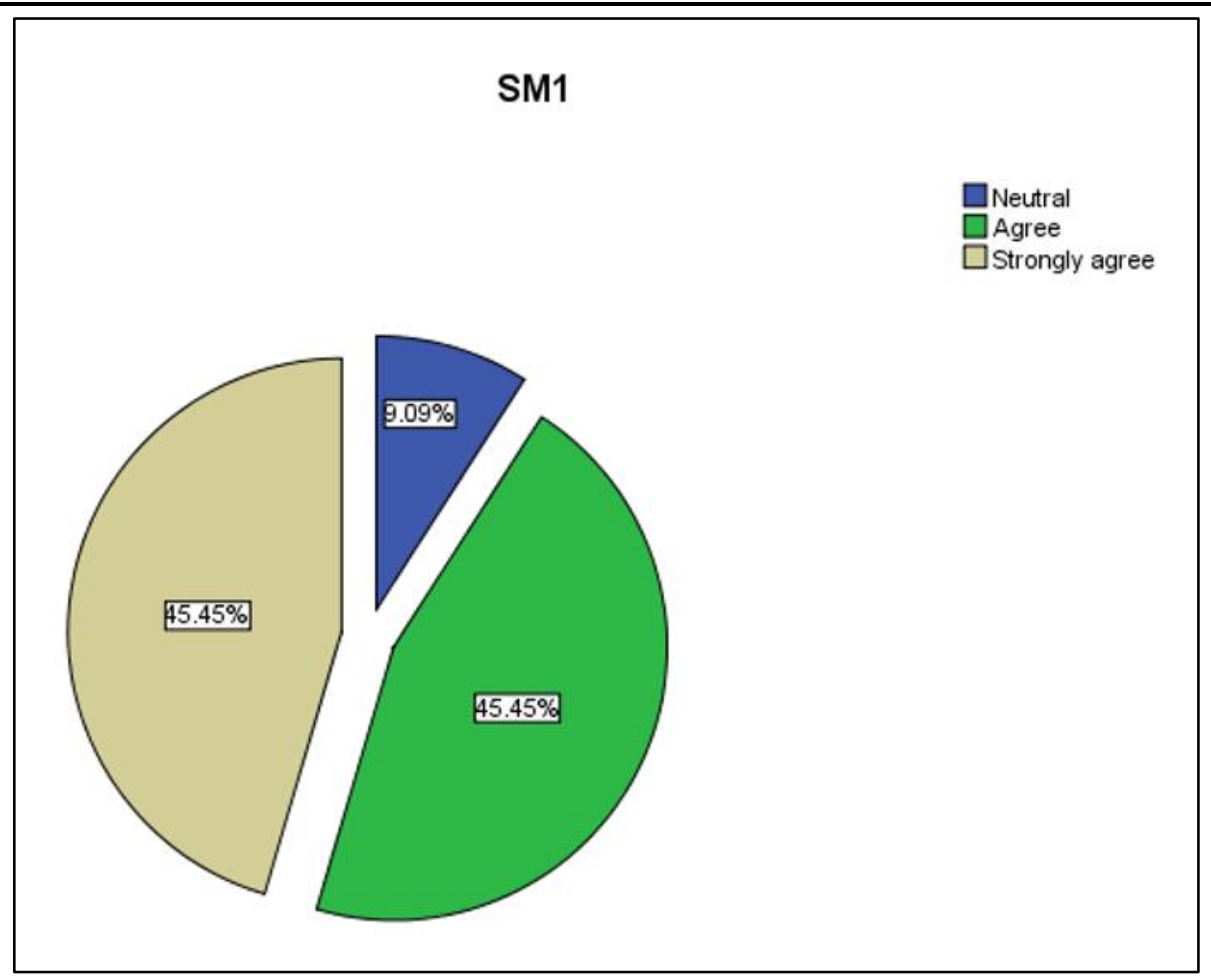

Figure 1: Virtual learning experience

The results of data analysis in Table 1 and Figure 1 show that most respondents ( 90\%) agree that they are satisfied with the virtual learning experience. Only $(10 \%)$ of the sample is neutral. Therefore, this statement is justified.

Statement 2: I think learning via the Direct English ecosystem and platforms is easier than the traditional one.

Table 2: The easiness of the direct English ecosystem and platforms than the traditional one SM2

\begin{tabular}{|l|l|c|c|c|c|}
\hline & & Frequency & Percent & Valid Percent & Cumulative Percent \\
\hline \multirow{3}{*}{ Valid } & Disagree & 2 & 9.1 & 9.1 & 9.1 \\
\cline { 2 - 6 } & Neutral & 2 & 9.1 & 9.1 & 18.2 \\
\cline { 2 - 6 } & Agree & 7 & 31.8 & 31.8 & 50.0 \\
\cline { 2 - 6 } & Strongly agree & 11 & 50.0 & 50.0 & 100.0 \\
\cline { 2 - 6 } & Total & 22 & 100.0 & 100.0 & \\
\hline
\end{tabular}




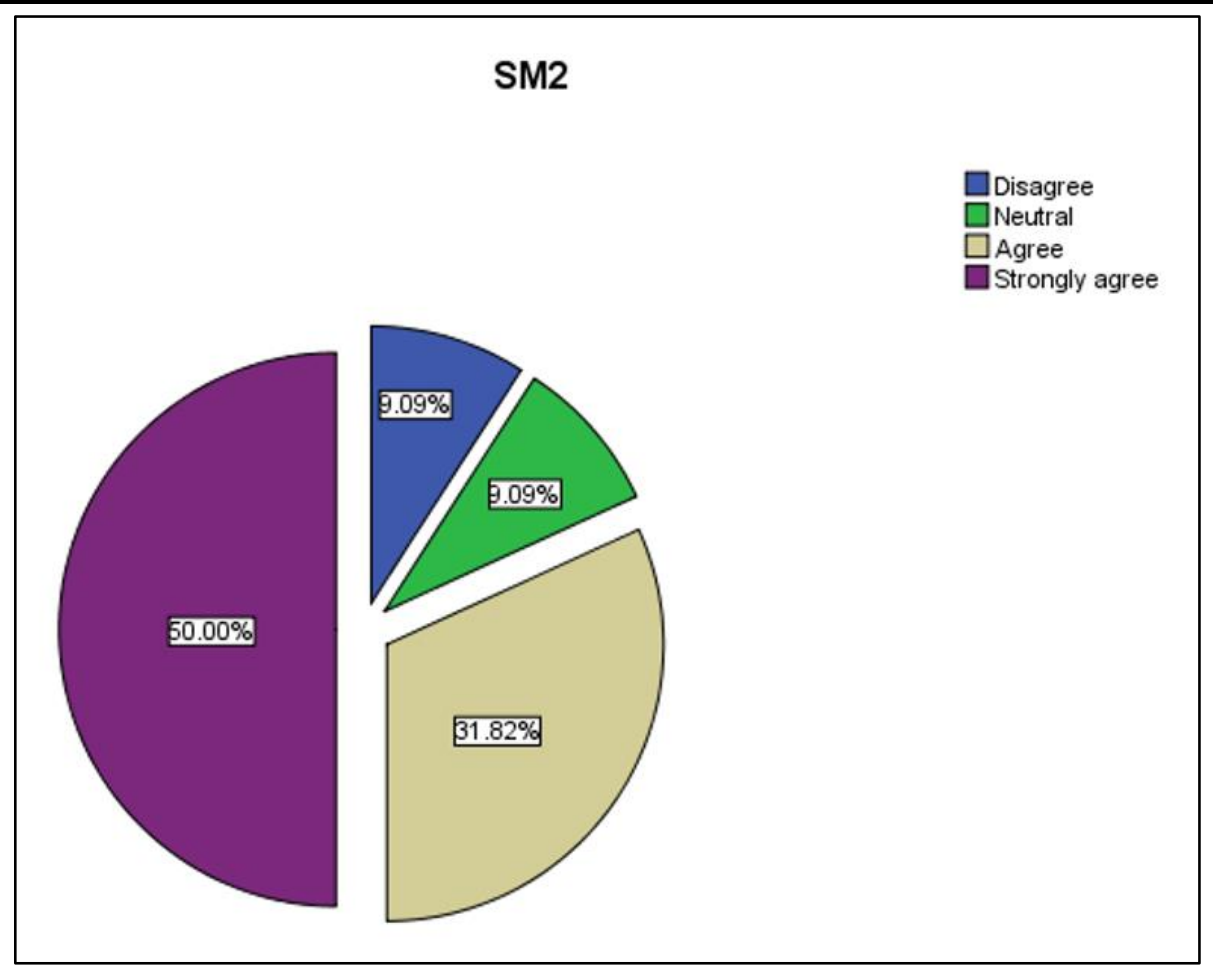

Figure 2: The easiness of direct English ecosystem and platforms than the traditional one

The statistical results in Table 1 and Figure 2 show that (51\%) of the sample strongly agree, $(31 \%)$ agree, $(9.1 \%)$ of the sample are neutral and $(9.1 \%)$ of the sample disagree that learning via Direct English ecosystem and platforms is easier than the traditional one. Thus, this statement is proved.

Statement 3: I am satisfied with Direct English blended learning services and tools.

Table 3: Satisfying with direct English blended learning services and tools SM3

\begin{tabular}{|l|l|c|c|c|c|}
\hline & & Frequency & Percent & Valid Percent & Cumulative Percent \\
\hline \multirow{3}{*}{ Valid } & Neutral & 2 & 9.1 & 9.1 & 9.1 \\
\cline { 2 - 6 } & Agree & 9 & 40.9 & 40.9 & 50.0 \\
\cline { 2 - 6 } & Strongly agree & 11 & 50.0 & 50.0 & 100.0 \\
\cline { 2 - 6 } & Total & 22 & 100.0 & 100.0 & \\
\hline
\end{tabular}




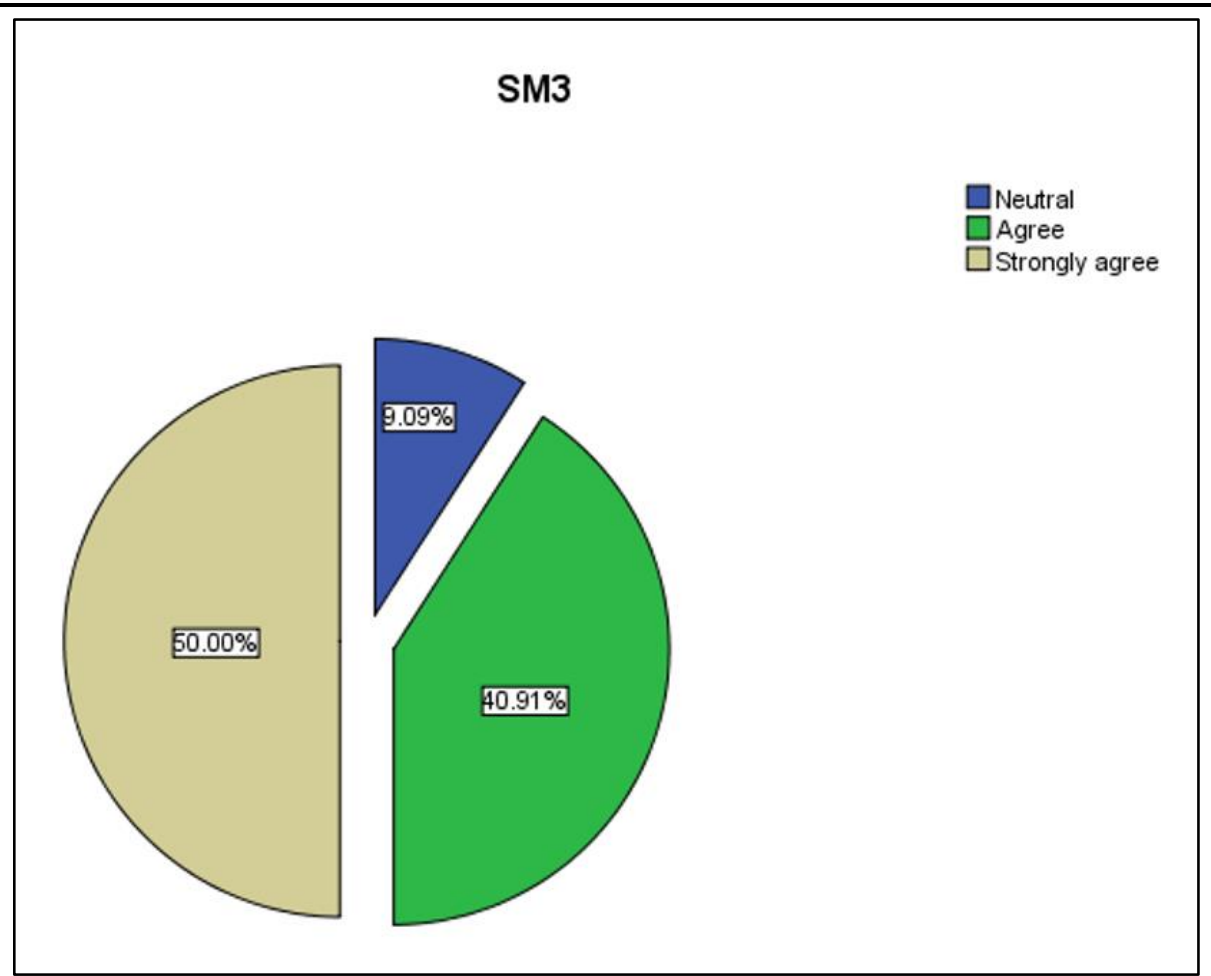

Figure 3: Satisfying with direct English blended learning services and tools

The statistical results in Table 3 and Figure 3 show that (50\%) of the sample strongly agree, $(40.9 \%)$ agree, $(9.1 \%)$ of the sample are neutral that they are satisfied with direct English blended learning services, and tools. Thus, this statement is accepted.

Statement 4: I prefer blended learning even after the end of the Covid19 pandemic.

Table 4: Preferring blended learning even after the end of Covid19 pandemic SM4

\begin{tabular}{|l|l|c|c|c|c|}
\hline & & Frequency & Percent & Valid Percent & Cumulative Percent \\
\hline \multirow{3}{*}{ Valid } & Disagree & 2 & 9.1 & 9.1 & 9.1 \\
\cline { 2 - 6 } & Neutral & 2 & 9.1 & 9.1 & 18.2 \\
\cline { 2 - 6 } & Agree & 12 & 54.5 & 54.5 & 72.7 \\
\cline { 2 - 6 } & Strongly agree & 6 & 27.3 & 27.3 & 100.0 \\
\cline { 2 - 6 } & Total & 22 & 100.0 & 100.0 & \\
\hline
\end{tabular}




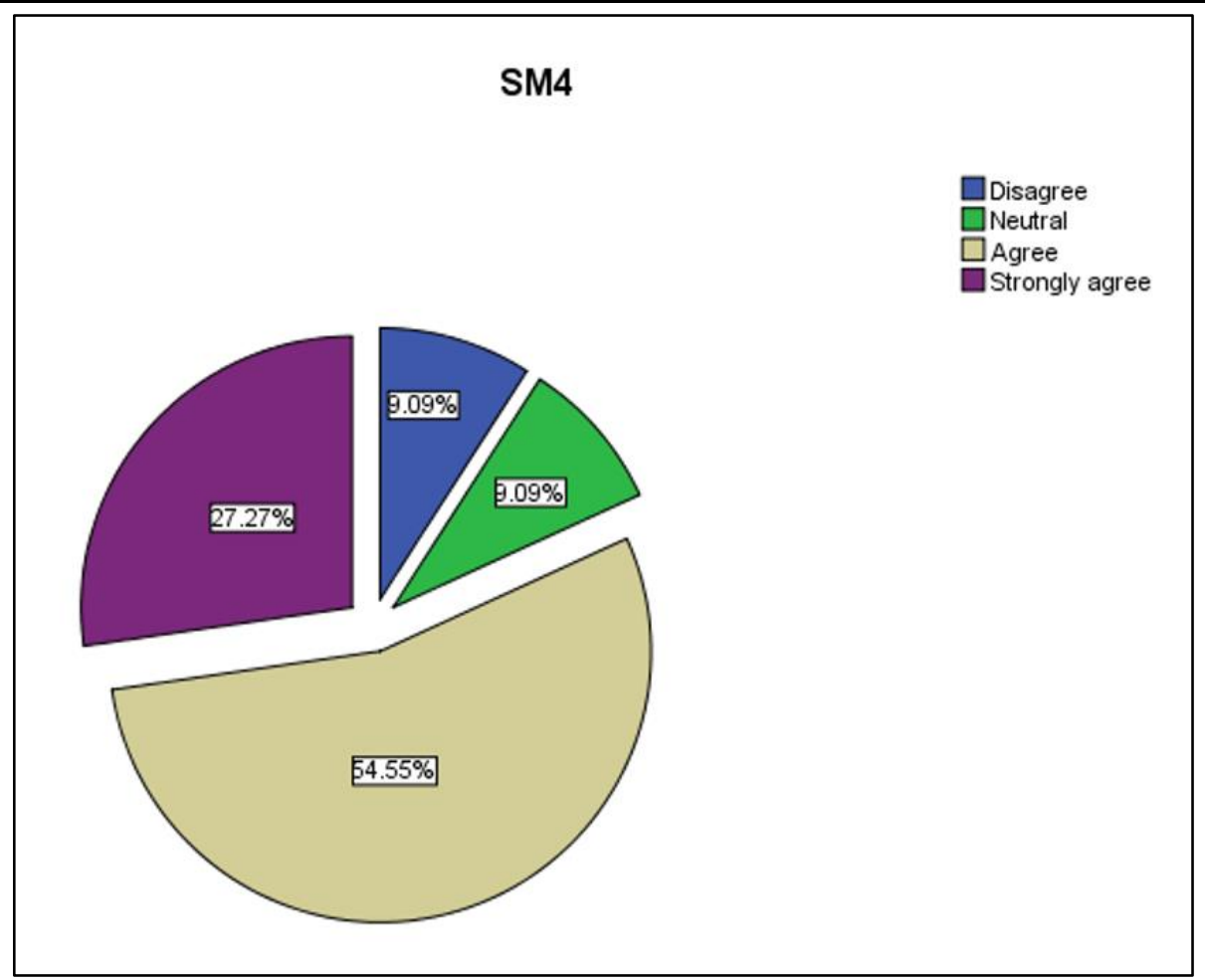

Figure 4: Preferring blended learning even after the end of Covid19 pandemic

According to the statistical analysis in Table 4 and Figure 4 (27.3\%) of the sample strongly agree, $(54.5 \%)$ of them agree, $(9.1 \%)$ of the sample are neutral, and $(9.1 \%)$ of them disagree that they prefer blended learning even after the end of Covid19 pandemic. Accordingly, this statement is justified.

Statement 5: Flip Learning (Membership program) provides many opportunities for teachers and learners to communicate.

Table 5: Providing many opportunities for teachers and learners to communicate SM5

\begin{tabular}{|l|l|c|c|c|c|}
\hline \multirow{3}{*}{ Valid } & & Frequency & Percent & Valid Percent & Cumulative Percent \\
\cline { 2 - 6 } & Neutral & 1 & 4.5 & 4.5 & 4.5 \\
\cline { 2 - 6 } & Agree & 11 & 50.0 & 50.0 & 54.5 \\
\cline { 2 - 6 } & Strongly agree & 10 & 45.5 & 45.5 & 100.0 \\
\cline { 2 - 6 } & Total & 22 & 100.0 & 100.0 & \\
\hline
\end{tabular}




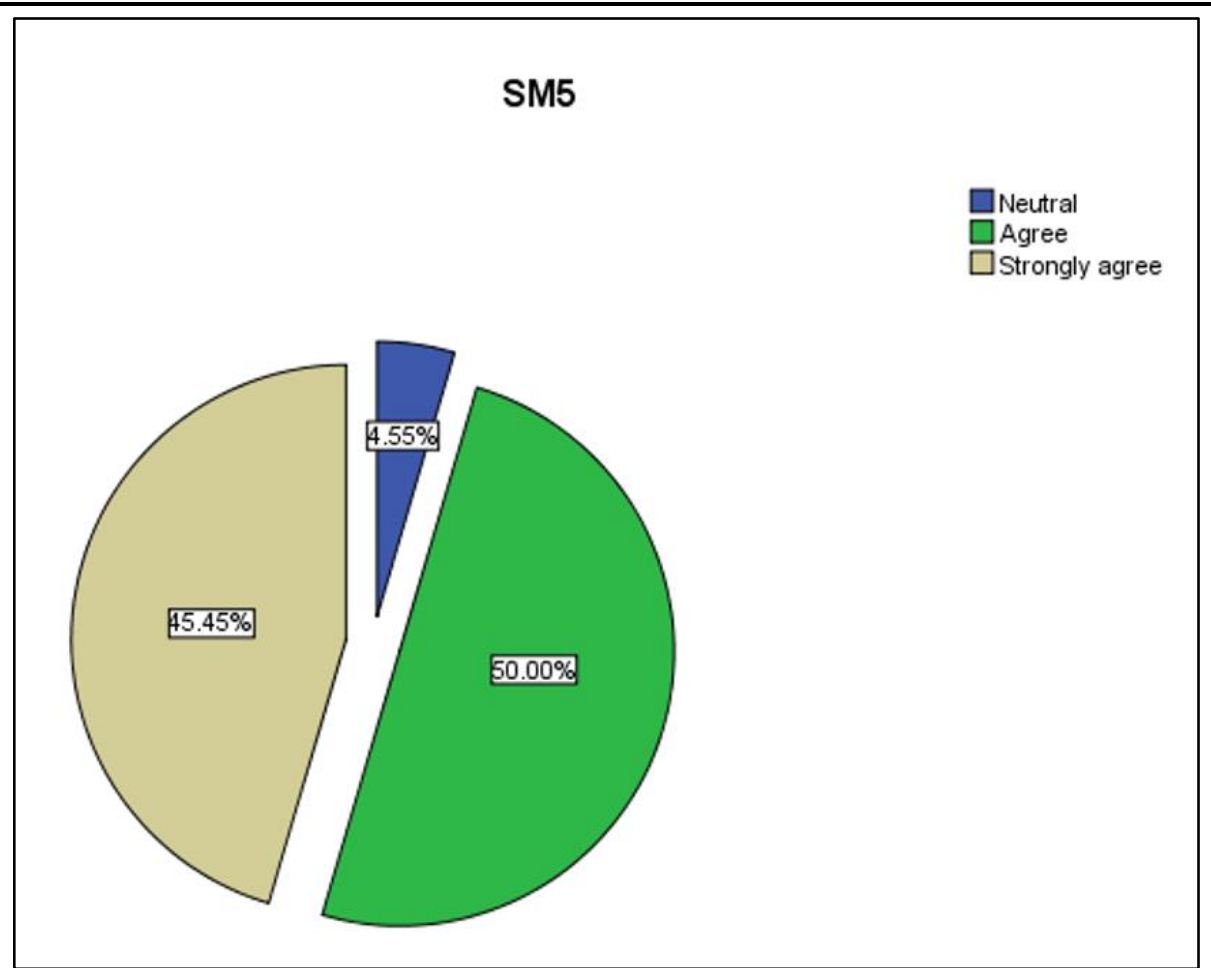

Figure 5: Providing many opportunities for teachers and learners to communicate

The analysis of the data in Table 5 and Figure 5 explains that $(50 \%)$ of the sample agree, $(45.5 \%)$ strongly agree, and $(4.5 \%)$ of the sample are neutral that flip learning provides many opportunities for teachers and learners to communicate. In accordance with these results, the statement is accepted.

Statement 6: Utilizing Flip Learning (Membership program) can improve learning, productivity, and performance.

Table 6: Utilizing Flip Learning can improve learning, productivity, and performance

\begin{tabular}{|l|l|c|c|c|c|}
\hline SM6 & \multicolumn{5}{|c|}{} \\
\hline \multirow{3}{*}{ Valid } & Neutral & 1 & Percent & Valid Percent & Cumulative Percent \\
\cline { 2 - 6 } & Agree & 13 & 5.5 & 4.5 & 4.5 \\
\cline { 2 - 6 } & Strongly agree & 8 & 36.4 & 59.1 & 63.6 \\
\cline { 2 - 6 } & Total & 22 & 100.0 & 10.4 & 100.0 \\
\hline
\end{tabular}




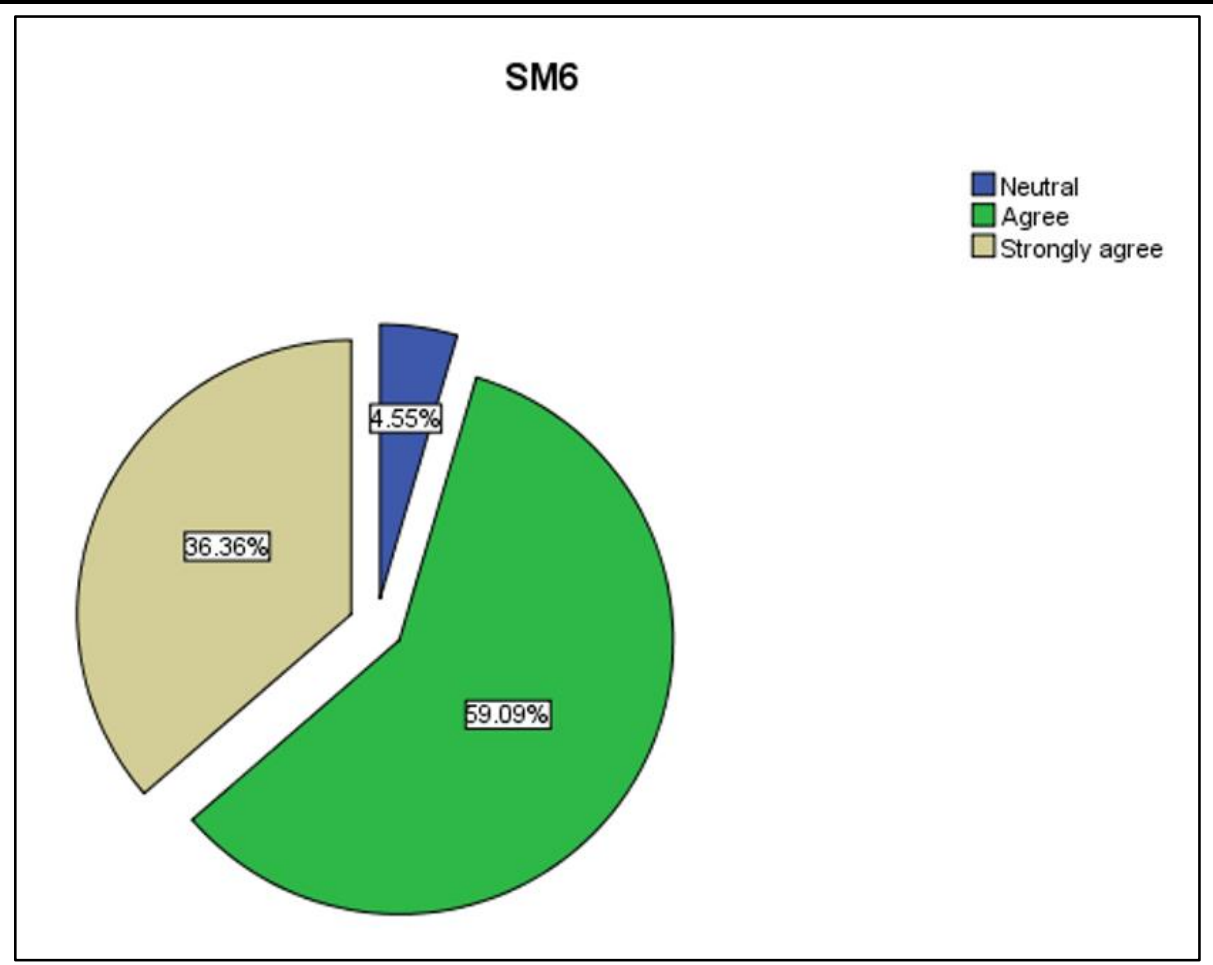

Figure 6: Utilizing Flip learning can improve learning, productivity, and performance

The statistical results in Table 6 and Figure 6 show that (36.4\%) of the sample strongly agree, $(59.1 \%)$ of them agree, and $(4.5 \%)$ are neutral that utilizing flip learning can improve learning, productivity, and performance. Thus, this statement is justified.

Statement 7: Learners are highly motivated due to the novelty of Flip Learning (Membership program) tools.

Table 7: Learners' motivation with flip learning tools

SM7

\begin{tabular}{|l|l|c|c|c|c|}
\hline \multirow{3}{*}{ Valid } & & Frequency & Percent & Valid Percent & Cumulative Percent \\
\cline { 2 - 6 } & Disagree & 1 & 4.5 & 4.5 & 4.5 \\
\cline { 2 - 6 } & Neutral & 3 & 13.6 & 13.6 & 18.2 \\
\cline { 2 - 6 } & Agree & 13 & 59.1 & 59.1 & 77.3 \\
\cline { 2 - 6 } & Strongly agree & 5 & 22.7 & 22.7 & 100.0 \\
\cline { 2 - 6 } & Total & 22 & 100.0 & 100.0 & \\
\hline
\end{tabular}




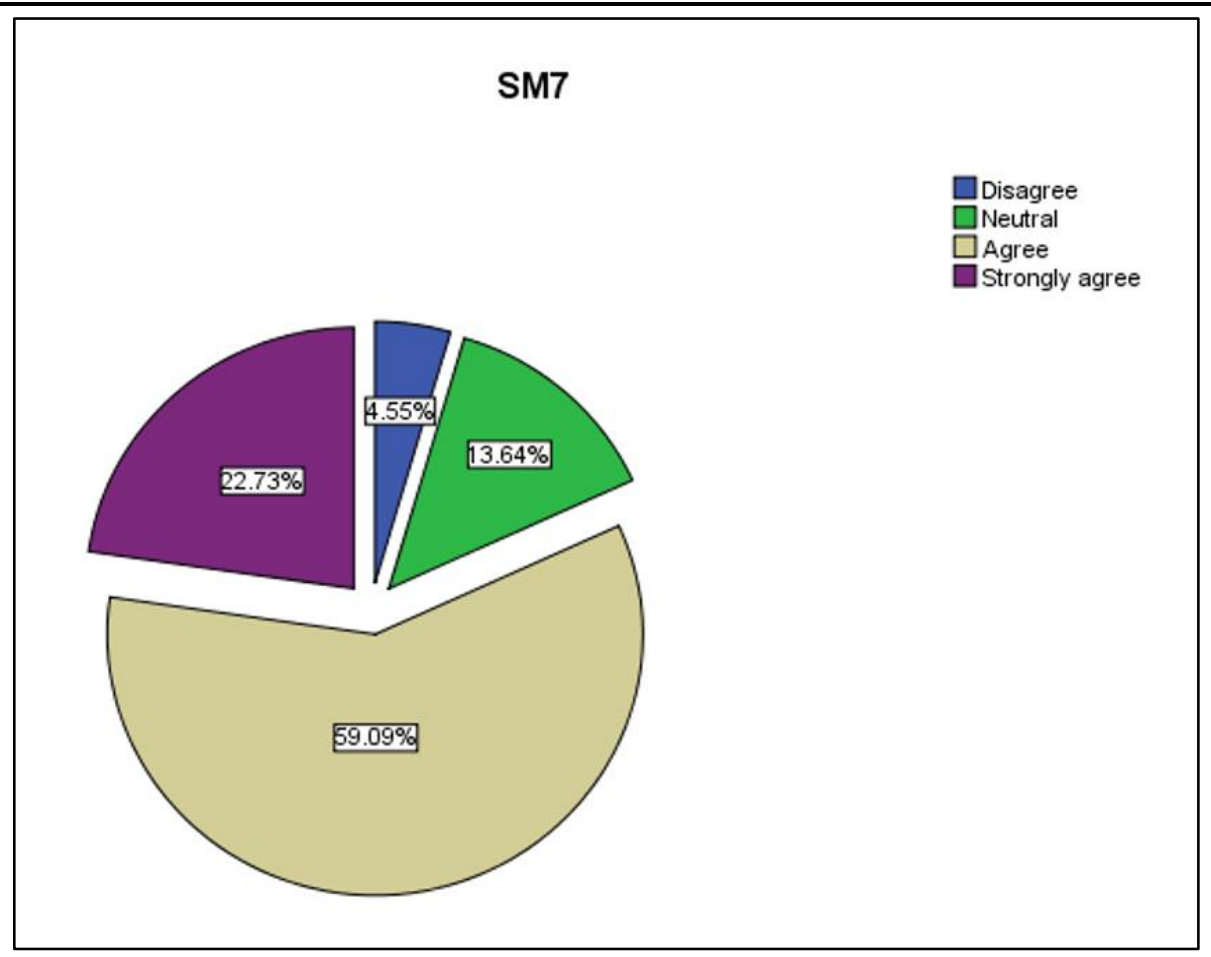

Figure 7: Learners' motivation with flip learning tools

The statistical results in Table 7 and Figure 7 show that $(22.7 \%)$ of the sample strongly agree, $(59.1 \%)$ of them agree, $(13.6 \%)$ of the sample are neutral, and $(4.5 \%)$ of them disagree that learners are highly motivated due to novelty of flip learning tools. Therefore, this statement is justified.

Statement 8: Direct English Ecosystem tools are active and manageable during the pandemic.

Table 8: English ecosystem tools are active and manageable during the pandemic

SM8

\begin{tabular}{|l|l|c|c|c|c|}
\hline & & Frequency & Percent & Valid Percent & Cumulative Percent \\
\hline \multirow{3}{*}{ Valid } & Agree & 12 & 54.5 & 54.5 & 54.5 \\
\cline { 2 - 6 } & Strongly agree & 10 & 45.5 & 45.5 & 100.0 \\
\cline { 2 - 6 } & Total & 22 & 100.0 & 100.0 & \\
\hline
\end{tabular}




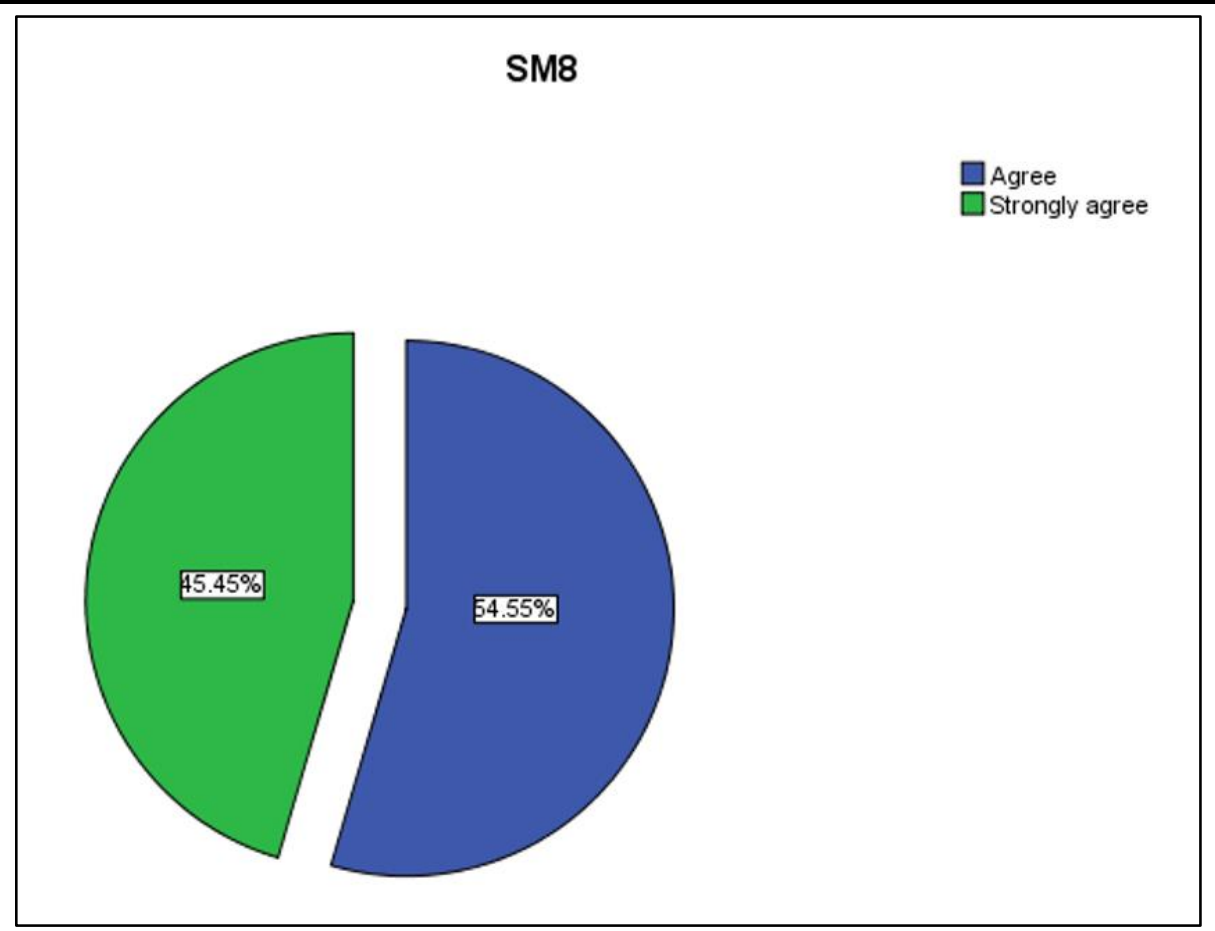

Figure 8: English ecosystem tools are active and manageable during the pandemic

The analysis of the data in Table 8 and Figure 8 shows that (45.5\%) of the sample strongly agree and (54.5\%) of them agree that direct English ecosystem tools are active and manageable during the pandemic. Accordingly, this statement is accepted.

Statement 9: Video listening tools are very supportive in flip learning (Membership program).

Table 9: Video listening tools are very supportive in flip learning

\begin{tabular}{|l|l|c|c|c|c|}
\hline SM9 & \multicolumn{5}{|c|}{} \\
\hline \multirow{3}{*}{ Valid } & Neutral & 1 & 4.5 & 4.5 & Cumulative Percent \\
\cline { 2 - 6 } & Agree & 8 & 36.4 & 36.4 & 40.9 \\
\cline { 2 - 6 } & Strongly agree & 13 & 59.1 & 59.1 & 100.0 \\
\cline { 2 - 6 } & Total & 22 & 100.0 & 100.0 & \\
\hline
\end{tabular}




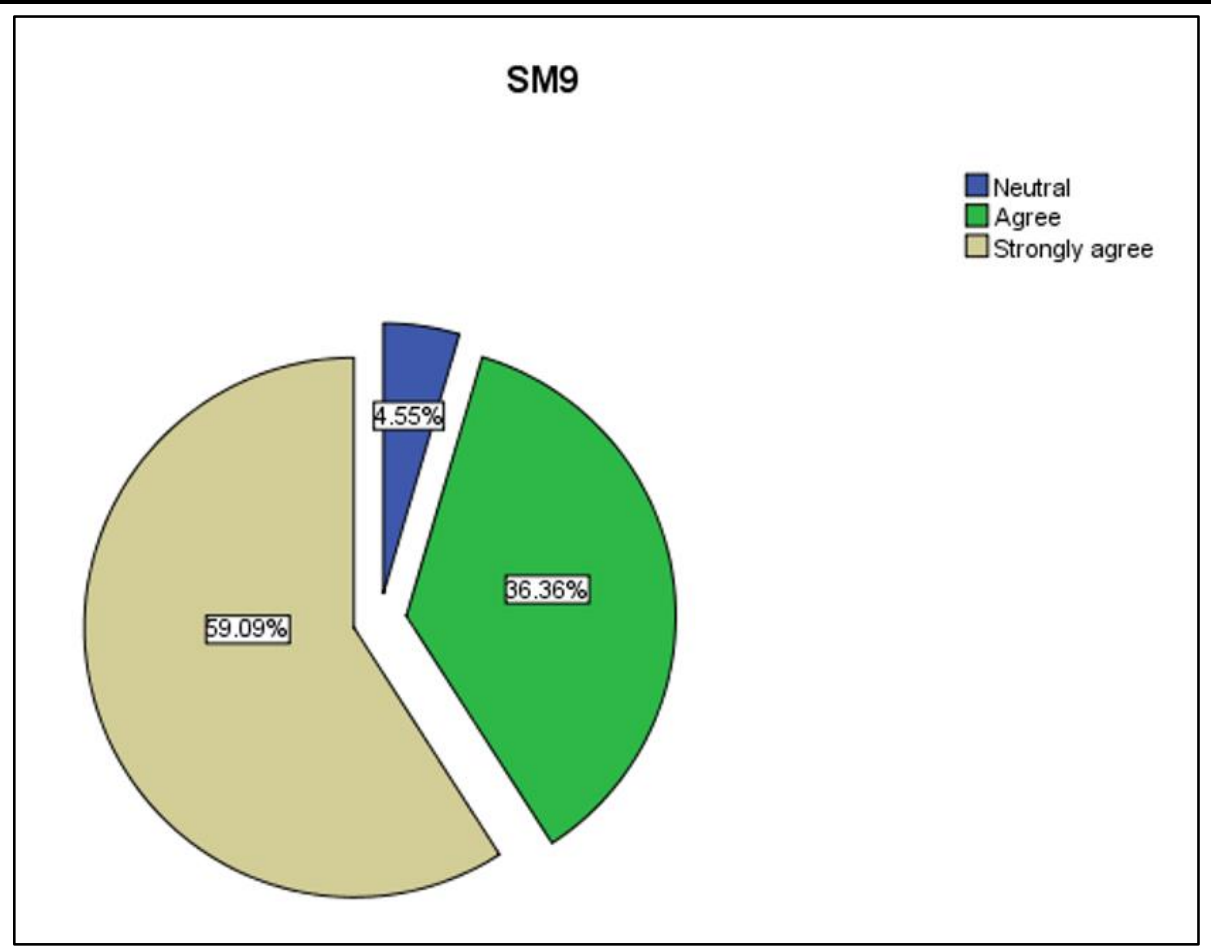

Figure 9: Video listening tools are very supportive in flip learning

The statistical results in Table 9 and Figure 9 show that most of the sample $(59.1 \%)$ strongly agree, $(36.4 \%)$ of the sample agree, and $(4.5 \%)$ of the sample are neutral that video listening tools are very supportive in flip learning. According to the statistical analysis, this statement is proved.

Statement 10: Educators who flip their classes are flexible in their expectations of student's timelines for learning and assessment.

Table 10: Educators who flip their classes

SM10

\begin{tabular}{|l|l|c|c|c|c|}
\hline \multirow{3}{*}{ Valid } & & Frequency & Percent & Valid Percent & Cumulative Percent \\
\cline { 2 - 6 } & Disagree & 1 & 4.5 & 4.5 & 4.5 \\
\cline { 2 - 6 } & Neutral & 3 & 13.6 & 13.6 & 18.2 \\
\cline { 2 - 6 } & Agree & 12 & 54.5 & 54.5 & 72.7 \\
\cline { 2 - 6 } & Strongly agree & 6 & 27.3 & 27.3 & 100.0 \\
\cline { 2 - 6 } & Total & 22 & 100.0 & 100.0 & \\
\hline
\end{tabular}




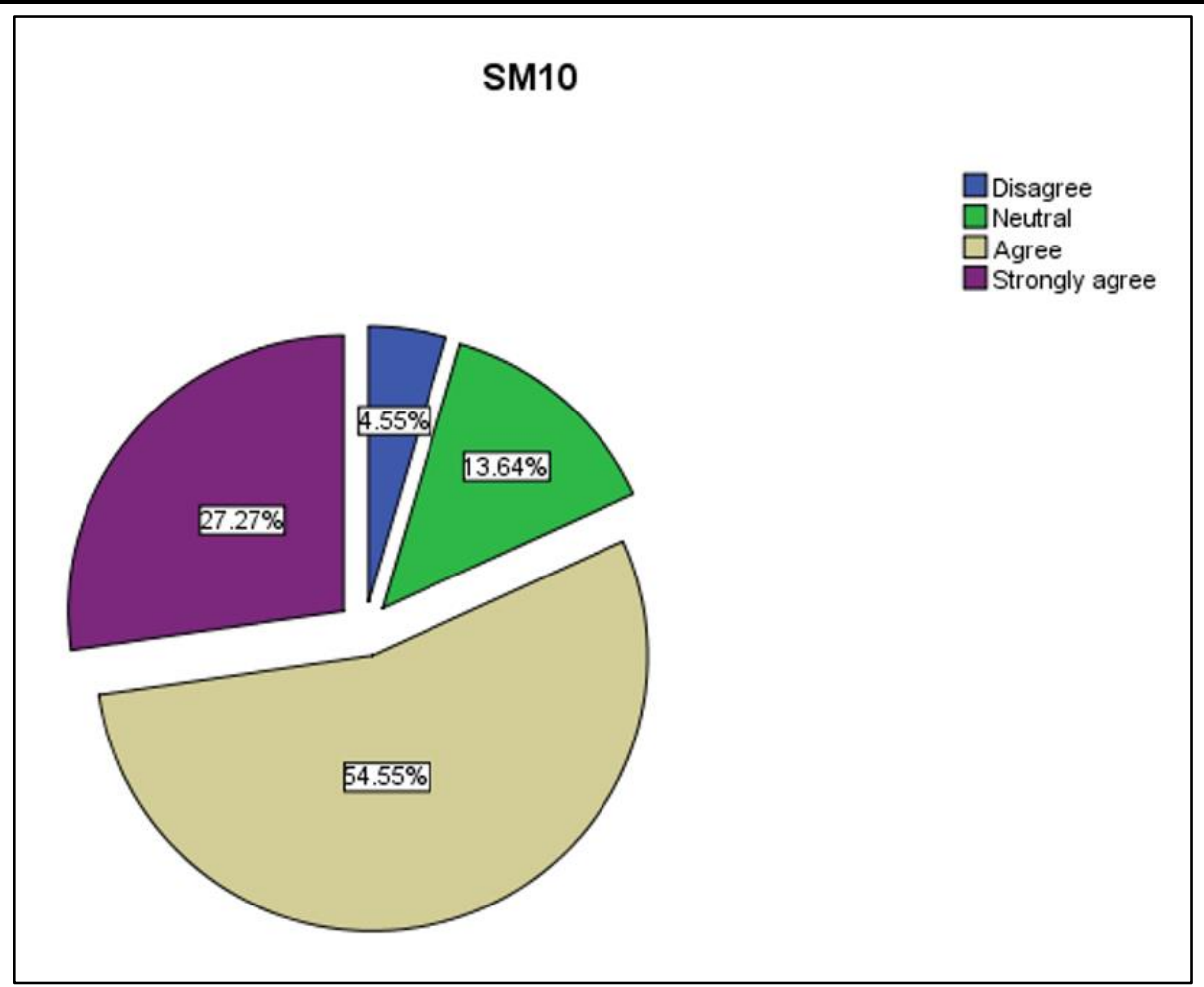

Figure 10: Educators who flip their classes

The statistical analysis of the data in Table and Figure 10 explains that $(27.3 \%)$ of the sample strongly agree, $(54.5 \%)$ of the sample agree, $(13.6 \%)$ of the sample are neutral, and (4.5\%) of them disagree that educators who flip their classes are flexible in their expectations of student's timelines for learning and assessment. In accordance with this, the statement is justified.

Statement 11: In the traditional teacher center model, the teacher is the primary source of information. By contrast, the flip learning (Membership program) model deliberately shifts the mode to a learner-centered approach.

Table 11: Flip learning model shift to a learner-centered approach

\section{SM11}

\begin{tabular}{|l|l|c|c|c|c|}
\hline & & Frequency & Percent & Valid Percent & Cumulative Percent \\
\hline \multirow{3}{*}{ Valid } & Disagree & 1 & 4.5 & 4.5 & 4.5 \\
\cline { 2 - 6 } & Neutral & 6 & 27.3 & 27.3 & 31.8 \\
\cline { 2 - 6 } & Agree & 8 & 36.4 & 36.4 & 68.2 \\
\cline { 2 - 6 } & Strongly agree & 7 & 31.8 & 31.8 & 100.0 \\
\cline { 2 - 6 } & Total & 22 & 100.0 & 100.0 & \\
\hline
\end{tabular}




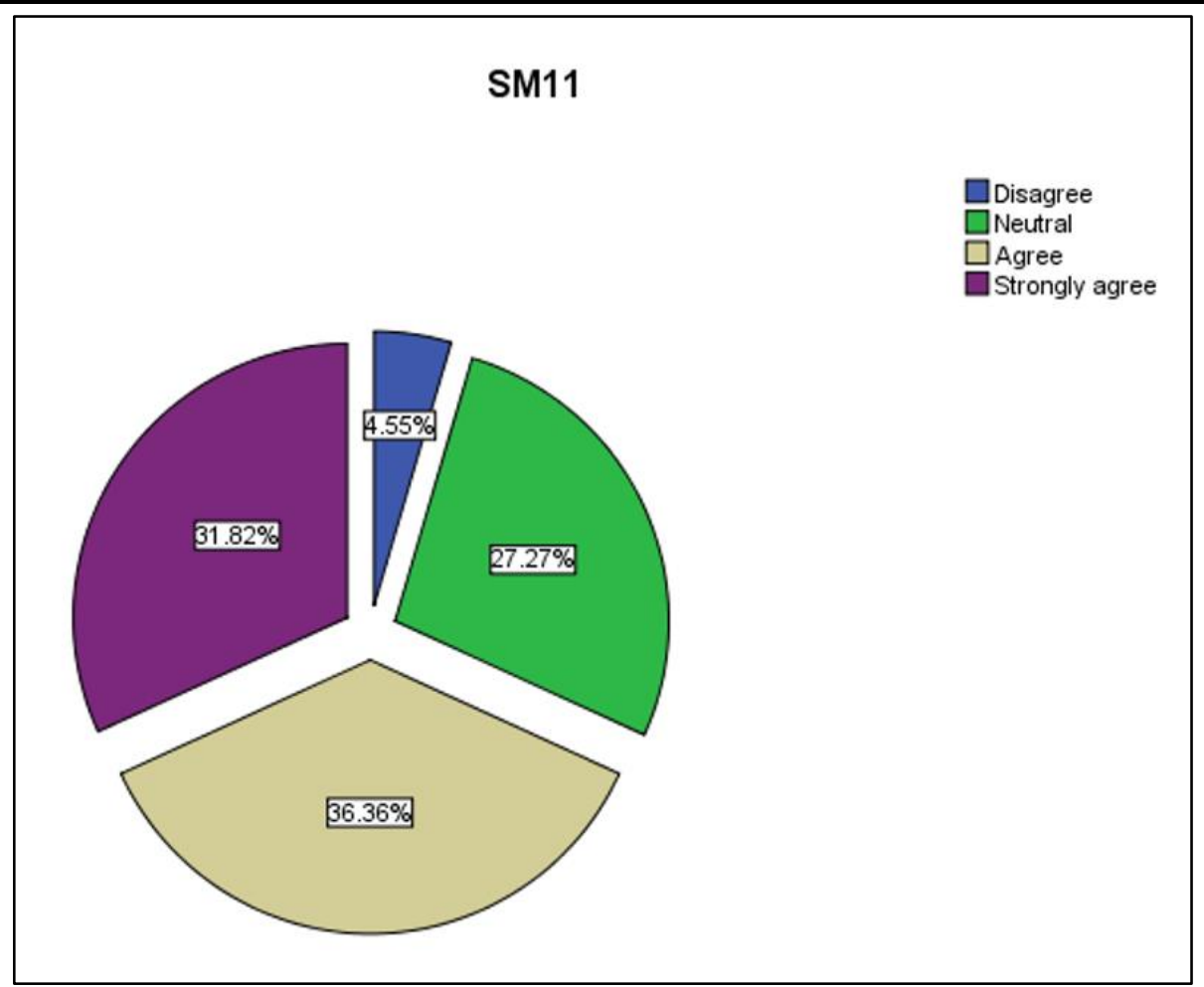

Figure 11: Flip learning model shift to a learner-centered approach

According to the statistical analysis in Table 11 and Figure 11, shows that $(31.8 \%)$ of the sample strongly agree, $(36.4 \%)$ of them agree, $(27.3 \%)$ of them are neutral, and $(4.5 \%)$ of the sample disagree that in the traditional teacher center model, the teacher is the primary source of information. By contrast, the flip learning model deliberately shifts the mode to a learnercentered approach. The statement is justified.

Statement 12: The role of a professional educator is even more critical and often moredemanding in a Flipped Classroom than in a traditional one.

Table 12: The role of a professional educator in a flipped classroom

SM12

\begin{tabular}{|l|l|c|c|c|c|}
\hline & & Frequency & Percent & Valid Percent & Cumulative Percent \\
\hline \multirow{3}{*}{ Valid } & Neutral & 4 & 18.2 & 18.2 & 18.2 \\
\cline { 2 - 6 } & Agree & 9 & 40.9 & 40.9 & 59.1 \\
\cline { 2 - 6 } & Strongly agree & 9 & 40.9 & 40.9 & 100.0 \\
\cline { 2 - 6 } & Total & 22 & 100.0 & 100.0 & \\
\hline
\end{tabular}




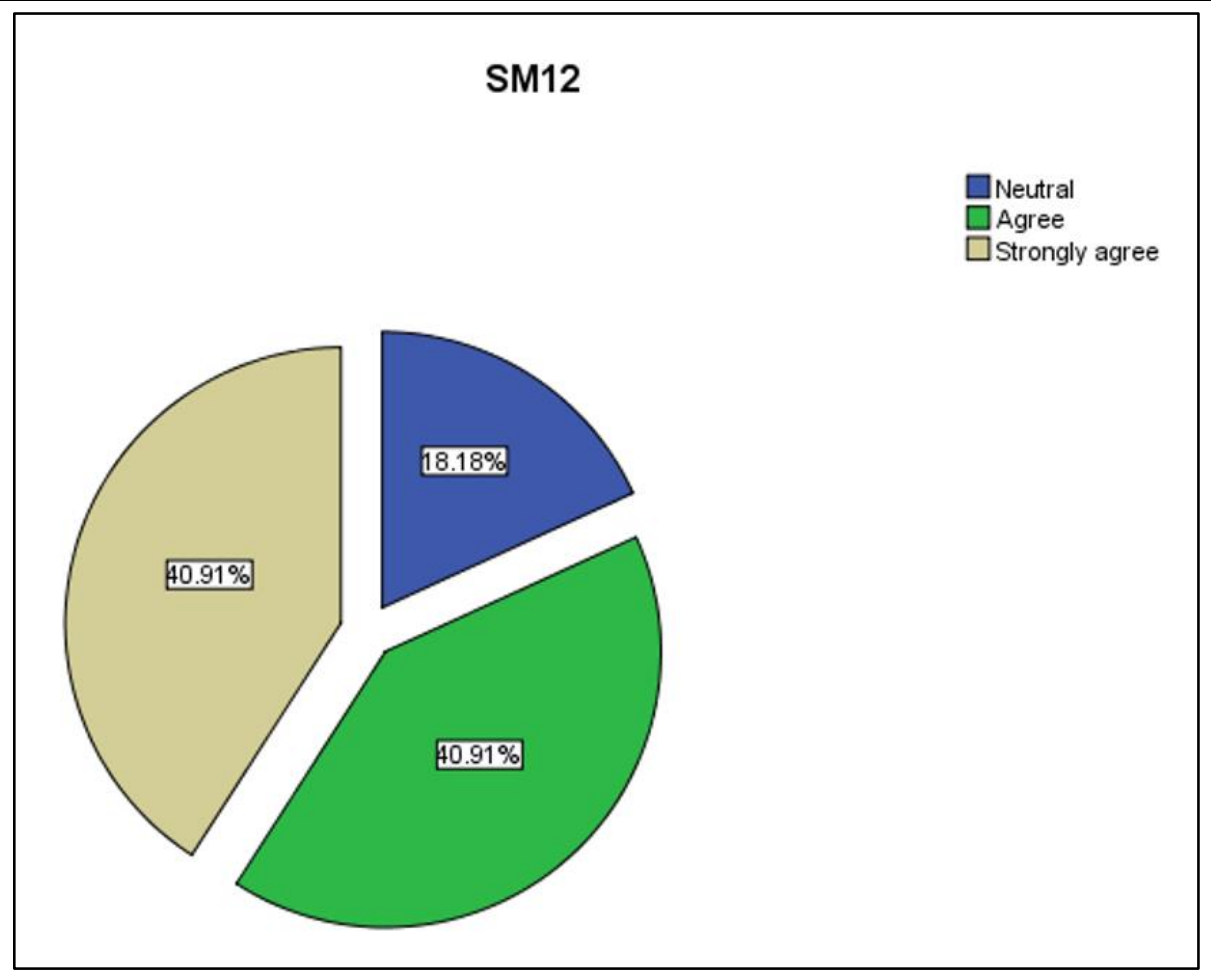

Figure 12: The role of a professional educator in a flipped classroom

The statistical results in Table 12 and Figure 12 show that (40.9\%) of the sample strongly agree, $(40.9 \%)$ of them agree, and $(18.2 \%)$ of them are neutral that the role of a professional educator is even more critical and often more demanding, in a flipped classroom than in a traditional one. Therefore, following this, this statement is accepted.

Table 13: Reliability statistics

Cronbach's Alpha .978

\section{Findings \& Conclusion}

Flipped Learning is an educational approach that combines the traditional classroom with online tools to find its best method in the Flipped classroom where the responsibility for the teaching process is someway shifted to the students who have direct access to the contents of the lesson before going to school.

Furthermore, the most appropriate way to carry out Flipped teaching has been to create virtual classes on social media such as Facebook, Edmodo, Zoom, and Microsoft Teams which are also helpful as a sort of online discussion forum between the teachers and their students. From this new perspective, students have experienced new techniques and methods through cooperative Learning, a teaching/learning model that allows them to figure together in small groups to achieve the same goals. Students can create digital products and posted them on Internet, thereby attaining great results. 
All the activities are planned to require under consideration critical thinking, different learning styles. In the end, they are supporting the idea of individual Learning rather than group learning.

\section{Recommendations}

This research was carried out in the initial phase of the Covid19 outbreak period on a small number of participants from teachers. The study recommended that other researchers would carry a larger scale population confirming the achieved results herein. The study includes and covers language centers in Saudi Arabia. The system can be expanded and implemented to solve any problem during pandemic lockdown periods and after.

\section{Conflict of Interest Statement}

With this, as authors of this paper, we declare that we have no conflicts interest.

\section{About the Authors}

Alwaleed Mohamed Abdullah Alshangiti is a General Manager, English Development Department at Alkahleej Training and Education, in Saudi Arabia. He is also a member of GEG Sudan. His training and research interests include TESOL, Teacher Development, and English language in training centers. He has joined several international conferences.

Rabab Alshaiekh Idres Musa is a lecturer at the University of Sattam in KSA, where she teaches TEFL, EAP/ESP; she also teaches English in various schools in Sudan. She holds a Ph.D. from the University of Sudan. Her research interests include EAP/ESP, second language acquisition, and foreign language teaching and learning literature.

\section{References}

Brame, C. (2013). Flipping the classroom. Vanderilt University Center for Teaching Four Pillars of F-L-I-PTM (2014) Flipped Learning Network (FLN).

Glaser, R. (1984). Education and thinking: The role of knowledge. American psychologist, 39(2), 93.

Lee, J., Lim, C. \& Kim, H. (2017). Development of an instructional design model for flipped learning in higher education Education Tech Research Dev 65, 427-453

Noora Hamdan and Patrick McKnight, PhD George Mason University, A Review flipped 2013 Learning-Flipped Learning Network

Flipped Learning Professional Development (2013) Pearson \& The Flipped Learning Network Retrieved from http://www.pearsonschool.com/flippedlearning

R. Capone, P. De Caterina, G. A. G. Mazza (2017). Blended Learning, Flipped Classroom And Virtual, EDULEARN17 Proceedings

Slomanson, W. R. (2014). Blended Learning: A Flipped Classroom Experiment Journal of Legal Education Vol. 64, No. 1 (), pp. 93-102. 
Creative Commons licensing terms

Author(s) will retain the copyright of their published articles agreeing that Creative Commons Attribution 4.0 International License (CC BY 4.0) terms will be applied to their work. Under the terms of this license, no permission is required from the author(s) or publisher for members of the community to copy, distribute, transmit or adapt the article content, providing a proper, prominent and unambiguous attribution to the authors in a manner that makes clear that the materials are being reused under permission of a Creative Commons License. Views, opinions, and conclusions expressed in this research article are views, opinions, and conclusions of the author(s). and European Journal of Literature, Language and Linguistics Studies shall not be responsible or answerable for any loss, damage, or liability caused in relation to/arising out of conflicts of interest, copyright violations, and inappropriate or inaccurate use of any kind of content related or integrated into the research work. All the published works are meeting the Open Access Publishing requirements and can be freely accessed, shared, modified, distributed, and used for educational, commercial, and non-commercial purposes under a Creative Commons Attribution 4.0 International License (CC BY 4.0). 